\title{
Wind Tunnel Testing on Start/Unstart Characteristics of Finite Supersonic Biplane Wing
}

\author{
Hiroshi Yamashita, ${ }^{1,2}$ Naoshi Kuratani, ${ }^{1,3}$ Masahito Yonezawa, ${ }^{1,3}$ Toshihiro Ogawa, \\ Hiroki Nagai, ${ }^{4}$ Keisuke Asai, ${ }^{4}$ and Shigeru Obayashi ${ }^{1}$ \\ ${ }^{1}$ Institute of Fluid Science, Tohoku University, Sendai 980-8577, Japan \\ ${ }^{2}$ Institut für Physik der Atmosphäre, Deutsches Zentrum für Luft- und Raumfahrt, 82234 Oberpfaffenhofen, Germany \\ ${ }^{3}$ Honda Red Co., Ltd., Haga 321-3321, Japan \\ ${ }^{4}$ Department of Aerospace Engineering, Tohoku University, Sendai 980-8579, Japan
}

Correspondence should be addressed to Hiroshi Yamashita; hiroshi.yamashita@dlr.de

Received 17 July 2013; Accepted 20 September 2013

Academic Editor: James J. McGuirk

Copyright (C) 2013 Hiroshi Yamashita et al. This is an open access article distributed under the Creative Commons Attribution License, which permits unrestricted use, distribution, and reproduction in any medium, provided the original work is properly cited.

\begin{abstract}
This study describes the start/unstart characteristics of a finite and rectangular supersonic biplane wing. Two wing models were tested in wind tunnels with aspect ratios of 0.75 (model A) and 2.5 (model B). The models were composed of a Busemann biplane section. The tests were carried out using supersonic and transonic wind tunnels over a Mach number range of $0.3 \leq M_{\infty} \leq 2.3$ with angles of attack of $0^{\circ}, 2^{\circ}$, and $4^{\circ}$. The Schlieren system was used to observe the flow characteristics around the models. The experimental results showed that these models had start/unstart characteristics that differed from those of the Busemann biplane (two dimensional) owing to three-dimensional effects. Models A and B started at lower Mach numbers than the Busemann biplane. The characteristics also varied with aspect ratio: model A $\left(1.3<M_{\infty}<1.5\right)$ started at a lower Mach number than model B $\left(1.6<M_{\infty}<1.8\right)$ owing to the lower aspect ratio. Model B was located in the double solution domain for the start/unstart characteristics at $M_{\infty}=1.7$, and model B was in either the start or unstart state at $M_{\infty}=1.7$. Once the state was determined, either state was stable.
\end{abstract}

\section{Introduction}

A sonic boom is caused by shock waves and expansion waves generated by a supersonic aircraft. As the sonic boom generates an impulsive noise at the ground, it produces undesirable effects on not only people but also animals and architecture. Sonic boom mitigation is thus required for the development of supersonic commercial aircraft $[1,2]$, and extensive studies have been carried out regarding this $[3,4]$. Recently, Kusunose et al. proposed the supersonic biplane theory [5-8] as a method of sonic boom mitigation. This theory enables significant reduction if not complete elimination of shock waves and expansion waves by the wave reduction and wave cancellation effects of a biplane configuration.

The concept of a Busemann biplane, which was first proposed by Busemann in $1935[9,10]$, forms the basis of supersonic biplane theory. Figure 1 shows the Busemann biplane (two dimensional) in a supersonic flow; this biplane consists of two half-diamond airfoils facing each other. Figure 1(a) shows the start state: compression (shock) waves generated from the leading edge of the elements are canceled by an expansion wave at the shoulder; the wave drag due to thickness is reduced significantly by the mutual cancellation of waves. Thus, the waves propagating outside the elements can be eliminated. Figure 1(b) shows the unstart state: a curved bow shock forms in front of the elements owing to the choked-flow phenomenon; the wave drag increases greatly. Naturally, a strong shock wave propagates to the ground. Although the Busemann biplane can be in either state at a design Mach number, sonic boom mitigation can only be in the start state. This issue is called the "start/unstart problem."

The start/unstart characteristics of the Busemann biplane have been investigated. Previous studies demonstrated that 
the characteristics are similar to those of a supersonic inlet diffuser [11-13]: the Busemann biplane is in either the start or unstart state at a design Mach number depending on its acceleration/deceleration profile. The characteristics also include flow hysteresis behavior (details are described in Section 2). For the next step, a boomless supersonic biplane (threedimensional aircraft configuration) should be designed on the basis of supersonic biplane theory. Figure 2 shows a conceptual drawing of this three-dimensional configuration. The airfoil shape consists of a Busemann biplane for sonic boom mitigation; the biplane wings are finite. Thus, the start/unstart characteristics of the finite biplane wings differ from those of the Busemann biplane (e.g., two dimensional characteristics). This is the fundamental issue that needs to be investigated.

This study investigated the start/unstart characteristics of finite rectangular supersonic biplane wings using experimental fluid dynamics. Two biplane models consisting of a Busemann biplane section with aspect ratios of 0.75 and 2.5 were tested in supersonic and transonic wind tunnels. The test was performed for $0.3 \leq M_{\infty} \leq 2.3$, including the design Mach number of $M_{\infty}=1.7$, at several angles of attack in the range of $0^{\circ} \leq \alpha \leq 4^{\circ}$. A Schlieren system was applied to observe flow characteristics around the models. The start/unstart characteristics of the models were compared with those of the Busemann biplane (two dimensional). In particular, the effects of three-dimensional flows and aspect ratio on the start/unstart characteristics were examined.

This paper is organized as follows. Section 2 presents the outline of the start/unstart characteristics of the Busemann biplane. Section 3 describes the wind tunnel facility, models, flow visualization system, and experimental conditions. Section 4 presents the results and discussion regarding the start/unstart characteristics of the two models. Finally, Section 5 concludes this study.

\section{Start/Unstart Characteristics of Busemann Biplane}

Figure 3 shows the start/unstart characteristics of a supersonic inlet diffuser. The characteristics are predicted by two limits: the Kantrowitz-Donaldson limit [14-17] and isentropic contraction limit [18]. Previous studies demonstrated that these two limits can be applied to predicting the start/unstart states of the Busemann biplane (two-dimensional) [11, 12]. The thick solid line in Figure 3 indicates the KantrowitzDonaldson limit. Once a bow shock is generated in front of the biplane, the Mach number set by the limit must be exceeded for the biplane to go from the unstart state to the start state. The limit is given by

$$
\frac{A_{t}}{A_{i}}=\left[\frac{(\gamma-1) M_{\infty}^{2}+2}{(\gamma+1) M_{\infty}^{2}}\right]^{1 / 2}\left[\frac{2 \gamma M_{\infty}^{2}-(\gamma-1)}{(\gamma+1) M_{\infty}^{2}}\right]^{1 /(\gamma-1)},
$$

where $A_{i}$ is the inlet area and $A_{t}$ is the throat area (crosssectional area at shoulder of Busemann biplane). The broken line refers to the isentropic contraction limit. As the Mach number decreases from the design point, the flow is choked at the throat at the Mach number predicted by the limit. A bow shock is formed in front of the biplane, and the Mach number becomes $M_{\infty}=1.0$ at the throat. The isentropic contraction limit is given by

$$
\frac{A_{t}}{A_{i}}=M_{\infty}\left[\frac{(\gamma-1) M_{\infty}^{2}+2}{\gamma+1}\right]^{-(\gamma+1) / 2(\gamma-1)} .
$$

If the design point is defined at $M_{\infty}=1.7$, the configuration of the Busemann biplane is determined as follows: the thickness-chord ratio of the biplane is $t / c=0.05$ (when the chord length is 1.0), $G / c=0.5$ ( $G$ is the distance between wing elements), and the wedge angle of the biplane is $5.7^{\circ}$. Thus, $A_{t} / A_{i}$ of the biplane is 0.8 as indicated by the dotted line in Figure 3 . This configuration achieves compression/expansion wave cancellation between the elements at the design point. To reach the design point from a subsonic regime, the biplane must first exceed the Mach number $M_{\infty}=2.18$, where the bow shock is swallowed backward between the wing elements, whereas the flow is choked at $M_{\infty}=1.63$. The biplane has a flow-hysteresis area over $1.63 \leq M_{\infty}<2.18$. The thin solid line in Figure 3 shows how the design point changes as a function of $M_{\infty}$ for the Busemann biplane with $t / c=0.05$.

\section{Supersonic and Transonic Wind Tunnel Tests}

3.1. Wind Tunnel. The wind tunnel test was carried out at the intermittent blowdown wind tunnels of the Institute of Space and Astronautical Science, Japan Aerospace Exploration Agency (ISAS/JAXA). Figure 4 shows the supersonic wind tunnel, and Table 1 lists the specifications of the supersonic and transonic wind tunnels. The supersonic wind tunnel could change the free-stream Mach number in increments of 0.1 over a range of $1.5 \leq M_{\infty} \leq 4.0$; the transonic wing tunnel could change it in increments of 0.1 over the range of $0.3 \leq M_{\infty} \leq 1.3$. The transonic wind tunnel could vary $M_{\infty}$ continuously from high to low values during a single wind tunnel run. This is called a Mach sweep run, which enables the time series of changes in the flow around the model to be measured. The cross-sectional area of the test section was $600 \mathrm{~mm} \times 600 \mathrm{~mm}$ for each tunnel. Circular windows were installed in the test section for flow observations; these windows were $\phi=600 \mathrm{~mm}$ in the supersonic wind tunnel and $\phi=400 \mathrm{~mm}$ in the transonic wind tunnel.

3.2. Models. Two models with different aspect ratios were tested: model $\mathrm{A}(\mathrm{AR}=0.75)$ and model $\mathrm{B}(\mathrm{AR}=2.5)$. Figure 5 shows drawings of the two test models. These models were constructed from free-machining stainless steel (SUS303) and consisted of rectangular wings. The crosssectional configurations were identical to the Busemann biplane discussed previously in Section 2: the design point was at $M_{\infty}=1.7$. Table 2 lists their specifications. Model A could not ensure two-dimensionality of flows between the wing elements owing to its low aspect ratio. However, model A was intentionally tested to investigate the threedimensional effect on the start/unstart characteristics. 
TABLE 1: Specifications of supersonic and transonic wind tunnels of ISAS/JAXA.

\begin{tabular}{lcc}
\hline & Supersonic wind tunnel & Transonic wind tunnel \\
\hline Type & Blowdown & Blowdown \\
Mach number range & $1.5-4.0$ & $0.3-1.3$ \\
Test section size & $600 \mathrm{~mm} \times 600 \mathrm{~mm}$ & $600 \mathrm{~mm} \times 600 \mathrm{~mm}$ \\
Window size & $\phi 600 \mathrm{~mm}$ & $\phi 400 \mathrm{~mm}$ \\
Flow duration & $\geq 30 \mathrm{~s}$ & $\geq 30 \mathrm{~s}$ \\
Total pressure & $\geq 149.1 \mathrm{kPa}$ & $\geq 149.1 \mathrm{kPa}$ \\
Test gas & Dry air & Dry air \\
\hline
\end{tabular}

TABLE 2: Specifications of test models.

\begin{tabular}{lcc}
\hline & Model A & Model B \\
\hline Chord length, $c$ & $80 \mathrm{~mm}$ & $40 \mathrm{~mm}$ \\
Thickness, $t$ & $4 \mathrm{~mm}$ & $2 \mathrm{~mm}$ \\
Distance between wing elements at leading and trailing edges, $G$ & $40 \mathrm{~mm}$ & $20 \mathrm{~mm}$ \\
Distance between wing elements at shoulder, $G^{*}$ & $32 \mathrm{~mm}$ & $16 \mathrm{~mm}$ \\
Span, $w$ & $60 \mathrm{~mm}$ & $100 \mathrm{~mm}$ \\
Aspect ratio, AR & 0.75 & 2.5 \\
$t / c$ & 0.05 & 0.05 \\
$G / c$ & 0.5 & 0.5 \\
\hline
\end{tabular}

Model design must allow for critical conditions associated with blockage and transient starting loads [19, 20]. The blockage ratio of the model cross-sectional area to the test section cross-sectional area was almost $1 \%$ (model at $\alpha=0^{\circ}$ ). This is the maximum recommended ratio in supersonic wind tunnel testing [21] and is a commonly used value in transonic wind tunnel testing that considers tunnel wall effects [22]. Model B had a larger aspect ratio than that of model A. However, model B had a smaller frontal projected area of the wing than model A.

The starting loads and strength calculations were carried out following the procedures described in [23]. The starting load was estimated by using the empirical starting load normal force coefficient [22]. In the estimation, the coefficient was 0.26 , the total model planform area-for example, model B-was $S=122 \times 10^{-4} \mathrm{~m}^{2}$, and the total pressure was $P_{0}=$ $300 \mathrm{kPa}$. The estimation indicated that the maximum load was $9.52 \times 10^{2} \mathrm{~N}$; this maximum load was generated at the starting condition of $M_{\infty}=2.3$.

Strength calculations were performed assuming that the maximum load acted at the leading edge of the wing. The moment arm from the leading edge to the root of the sting was $0.4 \mathrm{~m}$. The section modulus of the sting was $Z=960.1 \times$ $10^{-9} \mathrm{~m}^{3}$. The resulting maximum stress at the sting root was $\sigma_{\max }=396.5 \mathrm{MPa}$. As the yielding stress of the sting (SNCM430) was $\sigma_{Y}>685 \mathrm{MPa}$, the test was performed with a safety factor of almost 1.7.

Figure 6 shows the experimental setup for the test. The model was supported by the sting system in the tunnel. The wings were mounted with the support section connected to the sting. This support section could maintain the designed distance between the wing elements.

3.3. Flow Visualization. The Schlieren system was used for both the supersonic and transonic wind tunnel tests. Figure 7 shows a schematic of the system. Two paraboloidal mirrors
(Mizojiri Optical Co., Ltd., $\phi=0.6 \mathrm{~m} ; f=6 \mathrm{~m}$ ) and two planar mirrors (Mizojiri Optical, $\phi=0.3 \mathrm{~m}$ ) were set up for the system. A continuous light source was provided with a xenon lamp power supply (Ushio, XB-10201AA-A) and graded sealed xenon lamps (Ushio, UXL-1000P-O). The Schlieren images were captured with a color video camera (Sony, CCD-IRIS) at a sampling rate of $30 \mathrm{~Hz}$.

3.4. Experimental Conditions. Table 3 lists the experimental conditions used in the tests. Model A was tested in both the supersonic and transonic wind tunnels, while model B was only tested in the supersonic wind tunnel. The operating total pressure $P_{0}$ was determined by the recommended reference criterion for these tunnels. The Reynolds number was calculated on the basis of each chord length: $c=0.08 \mathrm{~m}$ (model A) and $c=0.04 \mathrm{~m}$ (model B). The Mach sweep runs were conducted in case 1 for $0.3 \leq M_{\infty} \leq 0.9$ and in case 2 for $0.6 \leq M_{\infty} \leq 1.3$. To observe the three-dimensional flow characteristics of a supersonic biplane wing, model A was tested at $\phi=90^{\circ}$ in cases 7-10. No test was carried out at $M_{\infty}=1.4$ because of the operating characteristics of these wind tunnels. The pitch pause technique was also used [22]: tunnel operation was started with the model held at $\alpha=0^{\circ}$. The model was driven to $\alpha=2^{\circ}$ and then stopped and held for a period of time (approximately $7 \mathrm{~s}$ ) to allow instrument stabilization. In the same way, the model was moved to $\alpha=4^{\circ}$. Finally, the model was returned to $\alpha=0^{\circ}$.

\section{Results and Discussion}

\subsection{Start/Unstart Characteristics of the Finite Supersonic Biplane Wings}

4.1.1. Model $A(A R=0.75)$. Figure 8 shows the Schlieren images of model A for $0.3 \leq M_{\infty} \leq 1.3$ at $\alpha=0^{\circ}$; 


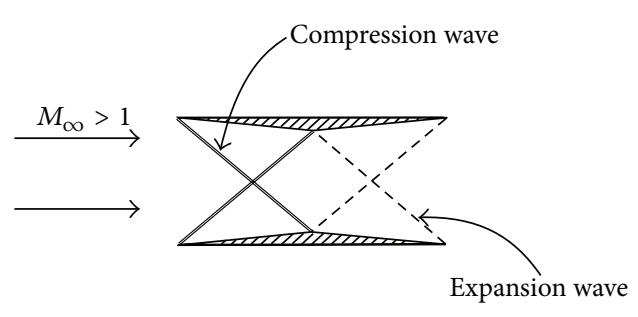

(a) Start state

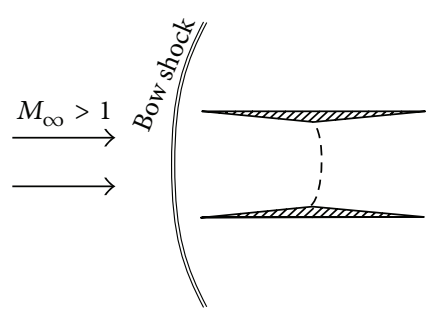

(b) Unstart state

FIGURE 1: Sketch of shock waves and expansion waves around Busemann biplane.

TABle 3: Experimental conditions. The Mach sweep is described in Section 3.1. The pitch pause is described in Section 3.4. In the pitch pause runs, $P_{0}$ represents the values of the first $\alpha=0^{\circ}$.

\begin{tabular}{|c|c|c|c|c|c|c|c|}
\hline Wind tunnel & Designation & Model & $M_{\infty}$ & $\alpha[\mathrm{deg}]$ & $\phi[\mathrm{deg}]$ & $P_{0}[\mathrm{kPa}]$ & $\operatorname{Re}\left[\times 10^{6}\right]$ \\
\hline \multirow{10}{*}{ Transonic } & Case 1 & $\mathrm{~A}$ & Mach sweep, $0.9-0.3$ & 0 & 0 & $150.5\left(M_{\infty}=0.9\right)-151.5\left(M_{\infty}=0.3\right)$ & $1.8-0.8$ \\
\hline & Case 2 & $\mathrm{~A}$ & Mach sweep, 1.3-0.6 & 0 & 0 & $150.6\left(M_{\infty}=1.3\right)-151.1\left(M_{\infty}=0.6\right)$ & $2.0-1.5$ \\
\hline & Case 3 & A & 1.0 & Pitch pause, $0-4$ & 0 & 150.5 & 1.9 \\
\hline & Case 4 & A & 1.1 & Pitch pause, $0-4$ & 0 & 150.3 & 1.9 \\
\hline & Case 5 & A & 1.2 & Pitch pause, $0-4$ & 0 & 150.6 & 2.0 \\
\hline & Case 6 & A & 1.3 & Pitch pause, $0-4$ & 0 & 151.0 & 1.9 \\
\hline & Case 7 & A & 1.0 & 0 & 90 & 150.7 & 1.9 \\
\hline & Case 8 & A & 1.1 & 0 & 90 & 150.3 & 1.9 \\
\hline & Case 9 & A & 1.2 & 0 & 90 & 150.6 & 2.0 \\
\hline & Case 10 & A & 1.3 & 0 & 90 & 150.8 & 2.0 \\
\hline \multirow{16}{*}{ Supersonic } & Case 11 & A & 1.5 & Pitch pause, $0-4$ & 0 & 200.2 & 2.4 \\
\hline & Case 12 & A & 1.6 & Pitch pause, $0-4$ & 0 & 201.1 & 2.4 \\
\hline & Case 13 & A & 1.7 & 0 & 0 & 200.5 & 2.3 \\
\hline & Case 14 & A & 1.7 & 2 & 0 & 201.1 & 2.3 \\
\hline & Case 15 & A & 1.7 & 4 & 0 & 200.4 & 2.3 \\
\hline & Case 16 & A & 1.8 & Pitch pause, $0-4$ & 0 & 200.6 & 2.2 \\
\hline & Case 17 & A & 1.9 & Pitch pause, $0-4$ & 0 & 200.4 & 2.1 \\
\hline & Case 18 & A & 2.1 & Pitch pause, $0-4$ & 0 & 250.4 & 2.5 \\
\hline & Case 19 & A & 2.3 & 0 & 0 & 301.4 & 2.7 \\
\hline & Case 20 & B & 1.5 & Pitch pause, $0-4$ & 0 & 200.7 & 1.2 \\
\hline & Case 21 & B & 1.6 & Pitch pause, $0-4$ & 0 & 200.7 & 1.2 \\
\hline & Case 22 & B & 1.7 & Pitch pause, $0-4$ & 0 & 201.4 & 1.1 \\
\hline & Case 23 & B & 1.8 & Pitch pause, $0-4$ & 0 & 200.2 & 1.1 \\
\hline & Case 24 & B & 1.9 & Pitch pause, $0-4$ & 0 & 200.0 & 1.0 \\
\hline & Case 25 & B & 2.0 & 0 & 0 & 249.8 & 1.3 \\
\hline & Case 26 & B & 2.1 & 0 & 0 & 250.8 & 1.2 \\
\hline
\end{tabular}

these images were taken by the Mach sweep runs of cases 1 and 2. Figure 8(a) shows a small variation in the subsonic flow density. At $M_{\infty}=0.6$, the flow changed gradually around the leading edge and at the shoulder. The flow accelerated between the elements as the area decreased, and the flow subsequently decelerated to the model exit as the area increased. As the Mach number increased in subsonic flow, a normal shock wave formed between the elements, and the supersonic flow area progressed to the aft part (Figure 8(c)). Figures $8(\mathrm{~d})-8(\mathrm{f})$ show that model $\mathrm{A}$ was in the unstart state at $M_{\infty}=1.0,1.1$, and 1.3 and that expansion clearly fanned at the shoulder. The bow shock formed ahead of the model at $M_{\infty}=1.0$, while the bow shock stood in front of the wing at $M_{\infty}=1.1$. The bow shock finally attached to the leading edge of the elements at $M_{\infty}=1.3$ before it was about to be swallowed.

Figure 9 shows the Schlieren images of model A for $1.5 \leq$ $M_{\infty} \leq 2.3$ at $\alpha=0^{\circ}$; these images were obtained from cases 11,13 , and 19 . The results confirmed that model A was in the start state for all Mach numbers including its design Mach number of $M_{\infty}=1.7$. At $M_{\infty}=1.7$, the shock wave from the leading edge almost hit the shoulder of the element. The resulting flow characteristics in Figure 9(b) are similar to the condition illustrated in Figure 1(a). For $M_{\infty}>1.7$, the shock angle from the leading edge decreased with increasing $M_{\infty}$. The shock wave hit the aft part on the wing surface, and 


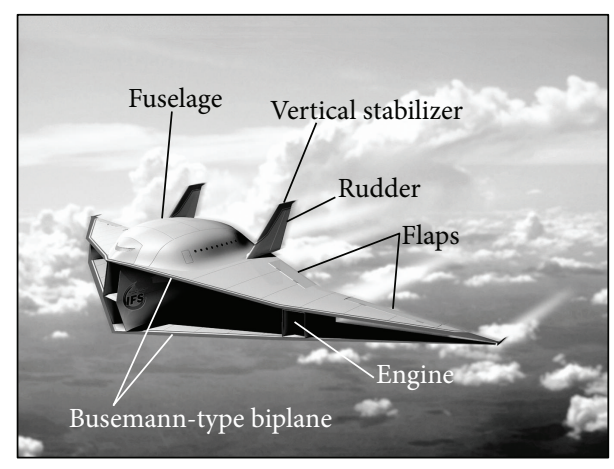

Figure 2: Conceptual drawing of boomless supersonic biplane in supersonic level flight [11]. The cross-sectional configuration of the wing is a Busemann-type biplane for sonic boom mitigation. The engines are mounted between the elements; the fuselage is placed on the wing. The cruise Mach number was assumed to be $M_{\infty}=1.7$.

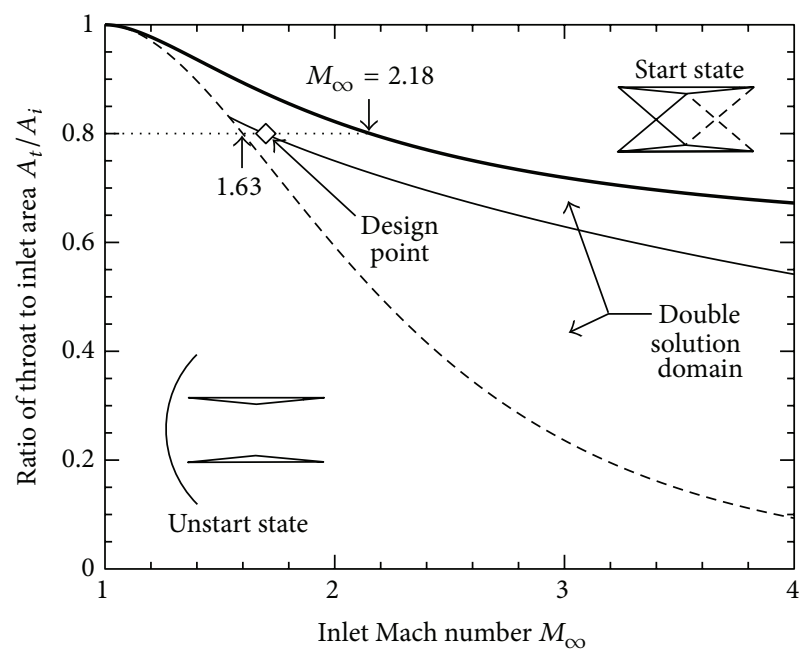

FIGURE 3: Start/unstart characteristics of supersonic inlet diffuser. The thick solid line shows the Kantrowitz-Donaldson limit, and the broken line shows the isentropic contraction limit. The ratio of the throat-to-inlet-area of the Busemann biplane is $A_{t} / A_{i}=0.8$ as indicated by the dotted line. The diamond symbol denotes the design point of the biplane at $M_{\infty}=1.7$ in this study. The thin solid line shows other design points of the Busemann biplane with $t / c=0.05$.

the wave reflected to the opposite side of the element. In other words, the compression/expansion wave interaction deviated from the condition illustrated in Figure 1(a). At $M_{\infty}=2.3$, the shock waves and expansion waves from the shoulder were visible separately between the elements. For $M_{\infty}>2.3$, model A was always in the start state. For $M_{\infty}<1.7$, on the other hand, the shock angle from the leading edge increased with decreasing $M_{\infty}$. Figure 9 (a) shows that the shock waves hit in front of the shoulder, and model A seemed about to go into the unstart state; however, it remained in the start state.

Figure 10 shows the time series Schlieren images of model $\mathrm{A}$ at $M_{\infty}=1.3$ and 1.5 during the pitch pause runs. Figure 10(a) shows that the bow shock deformed with increasing $\alpha$. However, the bow shock was not swallowed. The experimental results from cases 3-6 show that model A was always in the unstart state during the pitch pause runs

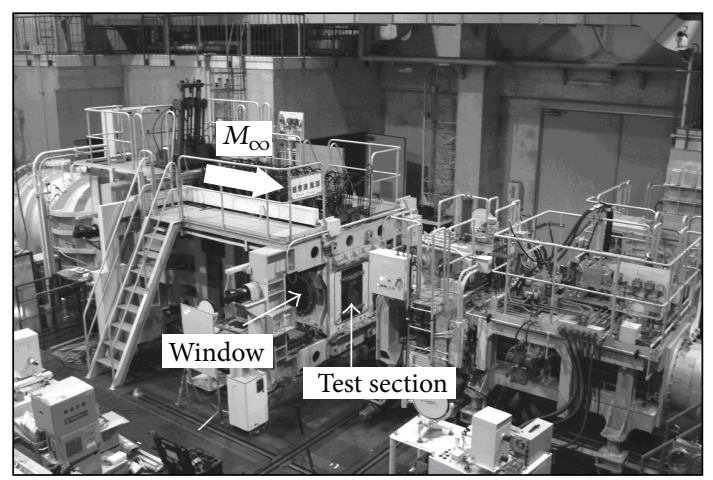

FIGURE 4: Supersonic wind tunnel facility of ISAS/JAXA. The test section is open to the atmosphere in the figure.

for $1.0 \leq M_{\infty} \leq 1.3$. On the other hand, Figure 10(b) shows that the shock wave from the leading edge of the upper element hit in front of the shoulder of the lower element with increasing $\alpha$. However, model A remained in the start state. The experimental results from cases 11,12 , and 16-18 showed that model A was always in the start state during the pitch pause runs for $1.5 \leq M_{\infty} \leq 2.1$. Thus, model A was deduced to transition into the start state when $1.3<M_{\infty}<1.5$ (no test was carried out at $M_{\infty}=1.4$ because of the operating characteristics of the wind tunnels).

It is important to mention here the effect of connecting pieces on the aerodynamics. A connecting piece is a prism shape attached to the top and bottom of the wing elements (Figure 5); the piece connects the biplane wing to the support section (Figure 6). Figures 8(f) and 10(a) show that the bow shock has attached to the leading edge and became oblique shocks at the outside. However, there was another strong bow shock on the outside of the wing elements, at around shoulder position. These bow shocks are probably due to the blockage of the connecting pieces. In supersonic condition and start states, their effect is likely small. However, in transonic condition and unstart states, it is difficult to imagine that the pressure rise due to the bow shocks has no effect on the aerodynamics inside of the wing elements, especially considering the low aspect ratio. The effect of these connecting pieces should be investigated in future studies.

4.1.2. Model $B(A R=2.5)$. Figure 11 shows the Schlieren images of model B for $1.5 \leq M_{\infty} \leq 2.1$ at $\alpha=0^{\circ}$; these images were obtained from cases $20,21,22$, and 26 . For $M_{\infty} \geq 1.7$, model $\mathrm{B}$ was in the start state, and the variations in flow characteristics with increases in $M_{\infty}$ were similar to those of model A. In contrast, model B was in the unstart state at $M_{\infty}=1.5$ and 1.6. The bow shock formed in front of the wing elements, and the flow became subsonic behind the bow shock. Model B expanded the flow from sonic speed at the shoulder to the aft part of the model.

Figure 12 shows the time series Schlieren images of model B at $M_{\infty}=1.6,1.7$, and 1.8 during the pitch pause runs. At $M_{\infty}=1.7$, model B was in the start state at the former $\alpha=$ $-0.1^{\circ}$ and $1.7^{\circ}$. However, model B was in the unstart state at $\alpha=3.7^{\circ}$ and the latter $-0.2^{\circ}$. These observations indicate that model $\mathrm{B}$ was located in the double solution domain shown in 


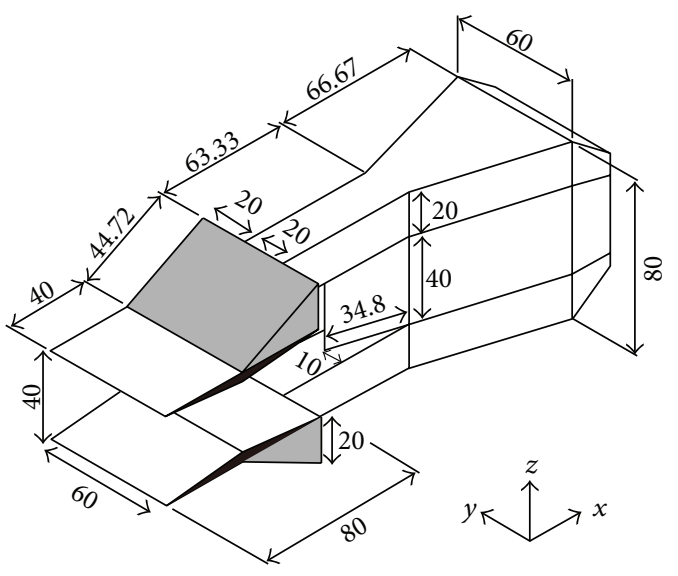

(a) Model A

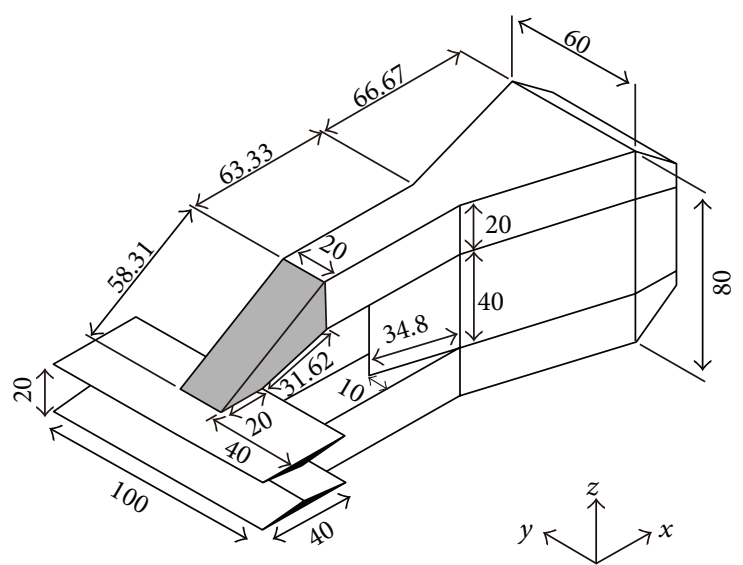

(b) Model B

FIGURE 5: Overview of finite rectangular supersonic biplane models. Both wings use the Busemann biplane section (shown in black). Numbers denote lengths (in $\mathrm{mm}$ ). Arrows indicate the positive direction. Shaded parts show connecting pieces.

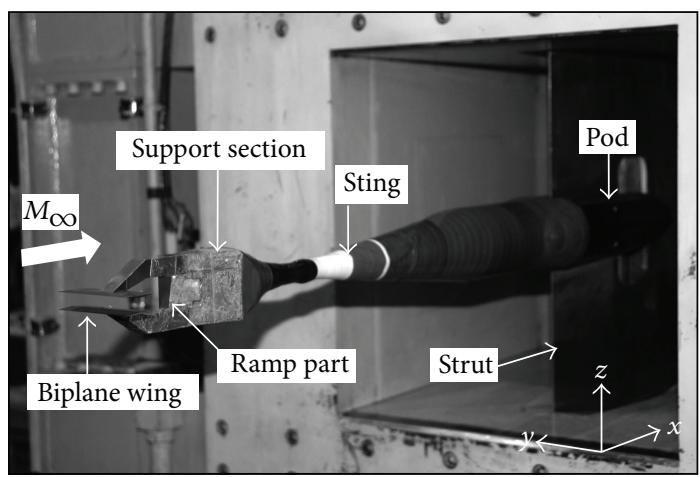

Figure 6: Wind tunnel model supported by sting in test section (model B).

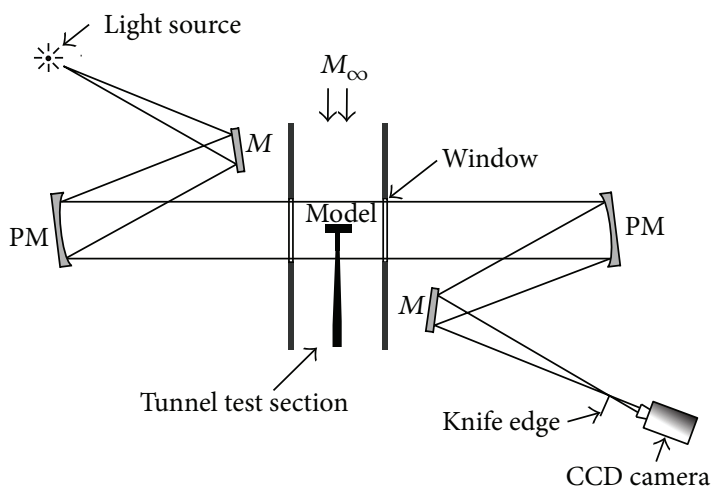

Figure 7: Schematic of Schlieren system for wind tunnel test. "PM" denotes a paraboloidal mirror; " $M$ " denotes a mirror.

Figure 3: model B was in either of the start/unstart states at $M_{\infty}=1.7$. Once the state was determined, either state was stable. The experimental results from cases 20 and 21 show that model B was always in the unstart state during the pitch pause runs at $M_{\infty}=1.5$ and 1.6, whereas the results from cases 23 and 24 show that model B was always in the start state during the pitch pause runs at $M_{\infty}=1.8$ and 1.9. Thus, model B transitioned into the start state when $1.6<M_{\infty}<$ 1.8 .

The implications of the difference in state between the former $\alpha=-0.1^{\circ}$ and latter $\alpha=-0.2^{\circ}$ were considered. The difference in $\alpha$ between $-0.1^{\circ}$ and $-0.2^{\circ}$ is negligible. If the progress of a normal shock during the wind tunnel starting process through a test section with model $\mathrm{B}$ is focused, two possible starting processes are expected. (I) If a normal shock passes across model B during the wind tunnel starting process, the normal shock is not swallowed backward between the wing elements. A bow shock forms in front of model B, and thus, the unstart state of model B is observed under the steady flow condition at $M_{\infty}=1.7$. (II) If nonuniform oblique shocks pass across model $B$ during the wind tunnel starting process, no bow shock forms in front of model B. Thus, a start state of model B is observed under steady flow conditions at $M_{\infty}=1.7$.

Irikado et al. [24, 25] investigated the starting shock characteristics of the present supersonic wind tunnel. They reported that nonuniform shocks usually pass through the test section during the wind tunnel starting process. The shock configuration changes according to the values of $M_{\infty}$ and $P_{0}$. The shock configuration also varies even under identical experimental conditions.

The former $\alpha=-0.1^{\circ}$ and latter $\alpha=-0.2^{\circ}$ probably showed different states because the experimental conditions of Figure 12(b) meet the requirements of starting process (II): model B was in the start state in the former image at $\alpha=-0.1^{\circ}$ because nonuniform shocks probably passed across model $\mathrm{B}$ during the wind tunnel starting process. Model $\mathrm{B}$ transitioned from the start state to the unstart state as $\alpha$ increased. Finally, model B was in the unstart state in the latter image at $\alpha=-0.2^{\circ}$. Note that all of the Schlieren images in Figure 12(b) showed the results under the steady flow condition at $M_{\infty}=1.7$. To demonstrate these considerations, the shock configuration passing across model B during the wind tunnel starting process needs to be observed for future work. 


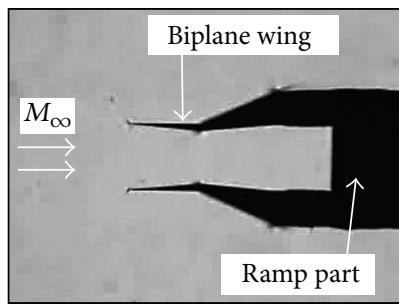

(a) $M_{\infty}=0.3$

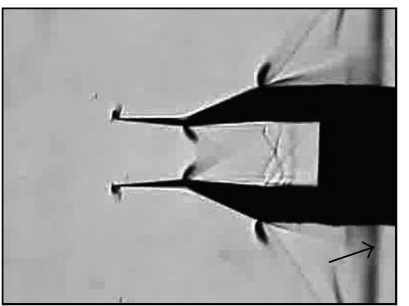

(d) $M_{\infty}=1.0$

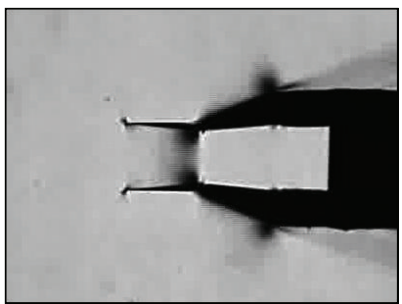

(b) $M_{\infty}=0.6$

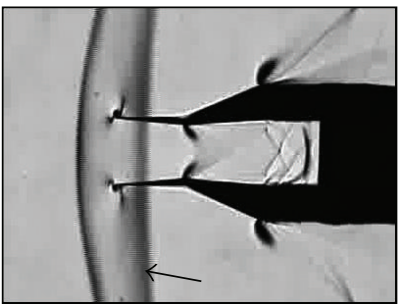

(e) $M_{\infty}=1.1$

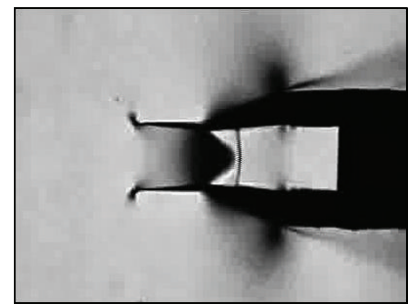

(c) $M_{\infty}=0.8$

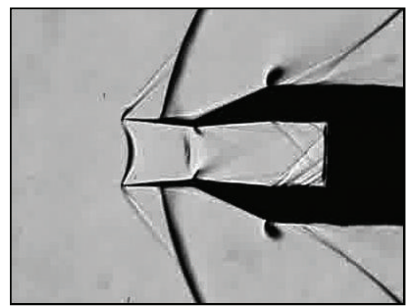

(f) $M_{\infty}=1.3$

FIGURE 8: Schlieren images of flow field around model A ( $\mathrm{AR}=0.75, \alpha=0^{\circ}, \beta=0^{\circ}$, and $\left.\phi=0^{\circ}\right)$. The images for $0.3 \leq M_{\infty} \leq 0.8$ were obtained from case 1 , and those for $1.0 \leq M_{\infty} \leq 1.3$ were obtained from case 2 . Arrows in (d) and (e) indicate reflected waves on the inner window.

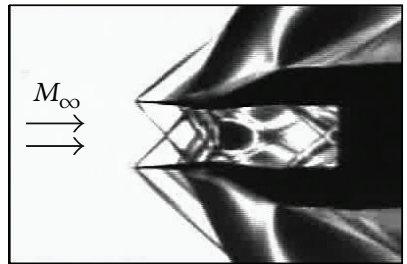

(a) $M_{\infty}=1.5$

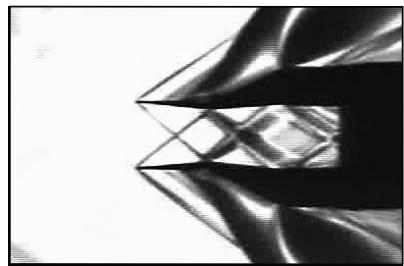

(b) $M_{\infty}=1.7$

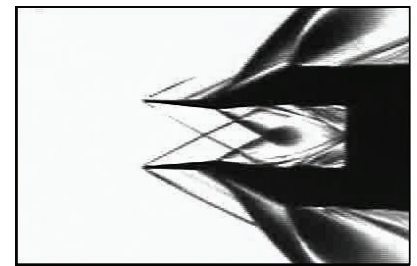

(c) $M_{\infty}=2.3$

Figure 9: Schlieren images of flow field around model $\mathrm{A}\left(\mathrm{AR}=0.75, \alpha=0^{\circ}, \beta=0^{\circ}\right.$, and $\left.\phi=0^{\circ}\right)$ : (a) $M_{\infty}=1.5$ (case 11$)$, (b) $M_{\infty}=1.7$ (case 13), and (c) $M_{\infty}=2.3$ (case 19).
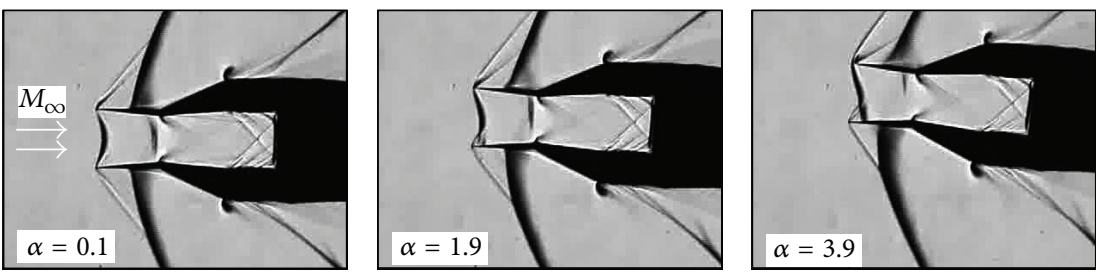

(a) $M_{\infty}=1.3$
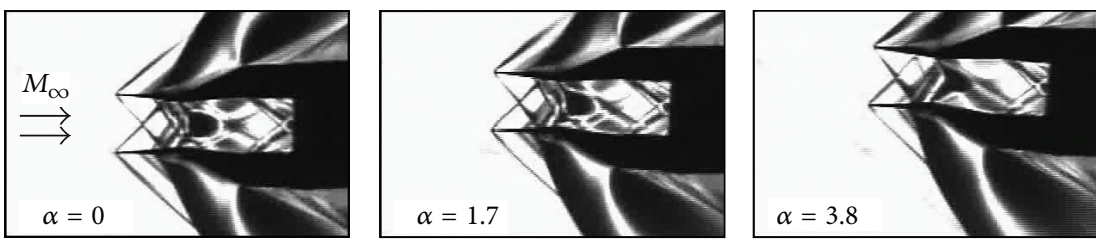

(b) $M_{\infty}=1.5$
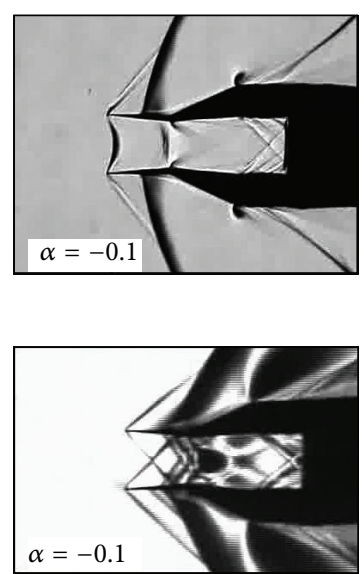

$\alpha=-0.1$

FIGURE 10: Time series Schlieren images of model A ( $\mathrm{AR}=0.75, \beta=0^{\circ}$, and $\left.\phi=0^{\circ}\right)$ during pitch pause runs: (a) $M_{\infty}=1.3$ (case 6$)$ and (b) $M_{\infty}=1.5$ (case 11). $\alpha$ denotes the resulting angles of attack (in ${ }^{\circ}$ ). The first image is on the left. 


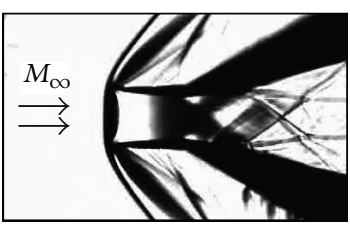

(a) $M_{\infty}=1.5$

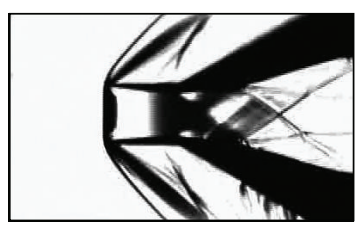

(b) $M_{\infty}=1.6$

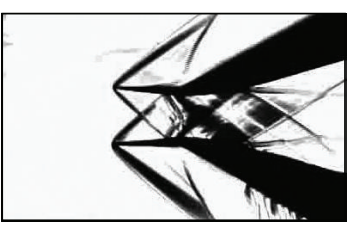

(c) $M_{\infty}=1.7$

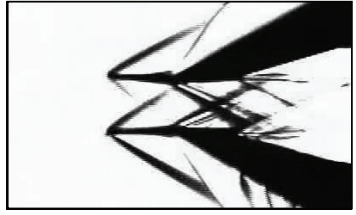

(d) $M_{\infty}=2.1$

FIGURE 11: Schlieren images of flow field around model B ( $\mathrm{AR}=2.5, \alpha=0^{\circ}, \beta=0^{\circ}$, and $\left.\phi=0^{\circ}\right)$ : (a) $M_{\infty}=1.5$ (case 20$)$, (b) $M_{\infty}=1.6$ (case 21), (c) $M_{\infty}=1.7$ (case 22), and (d) $M_{\infty}=2.1$ (case 26).
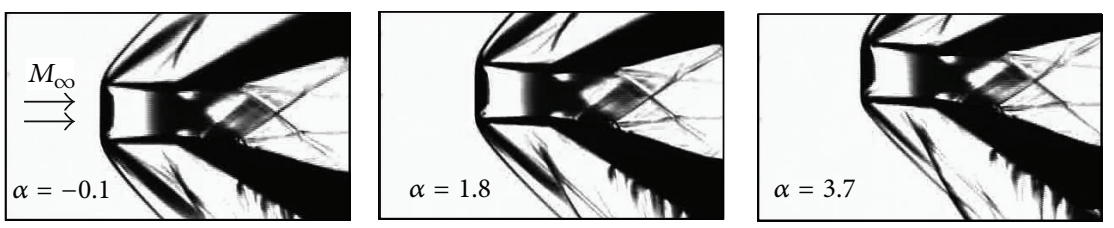

(a) $M_{\infty}=1.6$
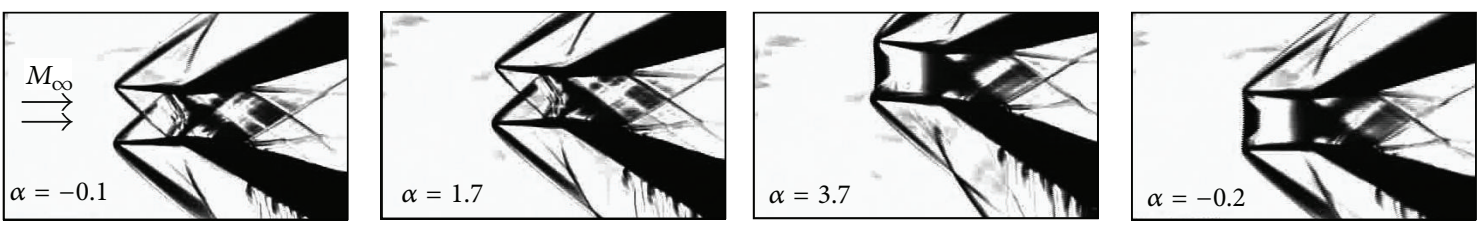

(b) $M_{\mathrm{\infty}}=1.7$
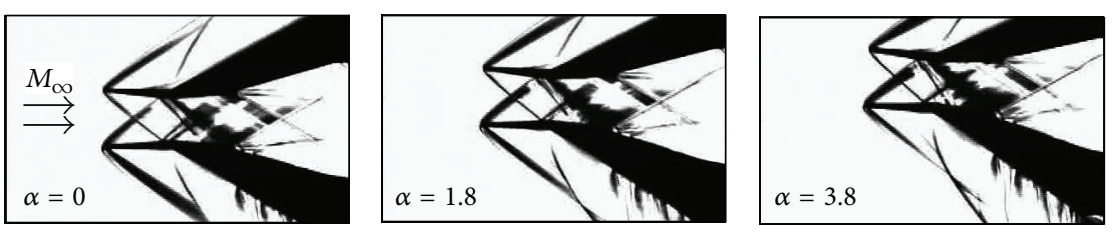

(c) $M_{\infty}=1.8$
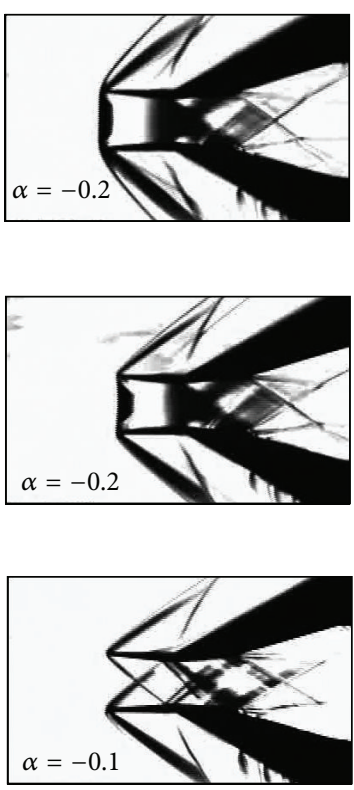

$\alpha=-0.1$

Figure 12: Time series Schlieren images of model $\mathrm{B}\left(\mathrm{AR}=2.5, \beta=0^{\circ}\right.$, and $\left.\phi=0^{\circ}\right)$ during pitch pause runs: (a) $M_{\infty}=1.6$ (case 21$)$, (b) $M_{\infty}=1.7$ (case 22), and (c) $M_{\infty}=1.8$ (case 23). $\alpha$ denotes resulting angles of attack (in ${ }^{\circ}$ ). The first image is on the left side.

4.2. Three-Dimensional Effect on the Start/Unstart Characteristics. The Busemann biplane (two dimensional) was in the start state at $M_{\infty}=2.18$ and in the unstart state at $M_{\infty}=1.63$ based on the limits given in Figure 3. In contrast, models $\mathrm{A}$ and $\mathrm{B}$ were in the start state at lower Mach number ranges owing to the three-dimensional effect. Figure 13 shows the Schlieren images of model A for $1.0 \leq M_{\infty} \leq 1.2$ at $\phi=90^{\circ}$. When model A was in the unstart state, the curved bow shock formed ahead of the wing, and the flow became subsonic behind the bow shock. The pressure between the wing elements was higher than that outside from the wing tip. The difference in static pressure produced a spilling flow around the wing tip from the high pressure side to the low pressure side. This spilling flow-that is, three-dimensional flow-relaxed the limits of the start/unstart characteristics in comparison with those of the Busemann biplane (two dimensional). Thus, the two models were in the start state at lower Mach numbers.

\subsection{Effects of Aspect Ratio on the Start/Unstart Characteristics.} The difference in start/unstart characteristics between models $\mathrm{A}$ and $\mathrm{B}$ is discussed here. The start/unstart characteristics varied with the aspect ratio. Model $A(A R=0.75)$ was in the start state at a lower Mach number $M_{\infty}=1.5$, as shown in Figure $9(\mathrm{a})$. However, model B $(\mathrm{AR}=2.5)$ was in the unstart state at $M_{\infty}=1.5$, as shown in Figure 11(a). This was due to the difference in the region of two-dimensional flows between the wing elements. Figure 14 shows the region of influence in supersonic flow on the models at $M_{\infty}=1.5$ based on linearized supersonic theory [10]. The broken line shows the Mach cone from each tip at $\mu=41.8^{\circ}$. The flow of the inner part behaved as a two-dimensional flow. Figure 14(a) shows that model $\mathrm{A}$ had a small region of two-dimensional flow owing to its low AR, whereas model B had a larger region between the tips owing to its high AR. When the region increased in size, the start/unstart characteristics became close to those of the Busemann biplane (two dimensional). Thus, model A reached the start state at lower $M_{\infty}$ than model B owing to its low AR.

\section{Conclusions}

The start/unstart characteristics of the finite rectangular supersonic biplane wings were investigated by wind tunnel tests for $0.3 \leq M_{\infty} \leq 2.3$; these tests included Mach 


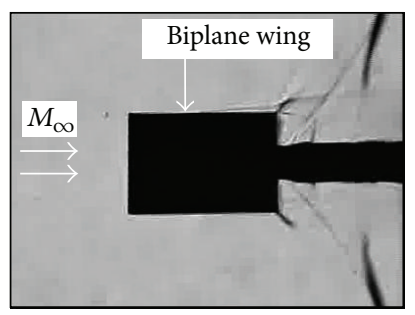

(a) $M_{\infty}=1.0$

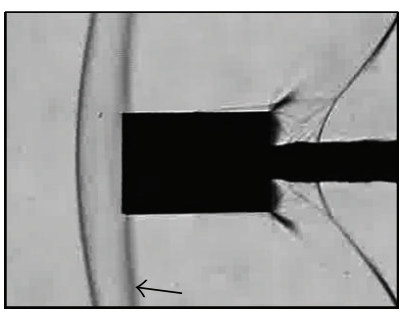

(b) $M_{\infty}=1.1$

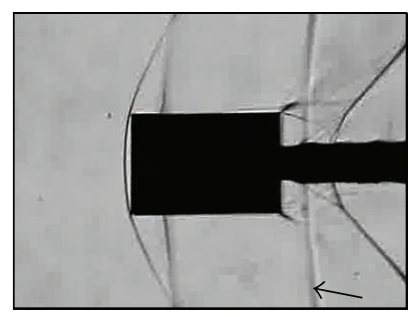

(c) $M_{\infty}=1.2$

FIGURE 13: Schlieren images of flow field around model A in unstart state (AR $=0.75, \alpha=0^{\circ}, \beta=0^{\circ}$, and $\left.\phi=90^{\circ}\right)$ : (a) $M_{\infty}=1.0$ (case 7), (b) $M_{\infty}=1.1$ (case 8), and (c) $M_{\infty}=1.2$ (case 9). Arrows in (b) and (c) indicate reflected waves on the inner window.

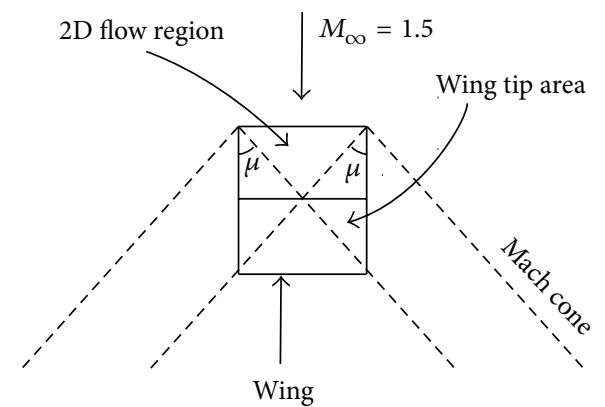

(a) Model A

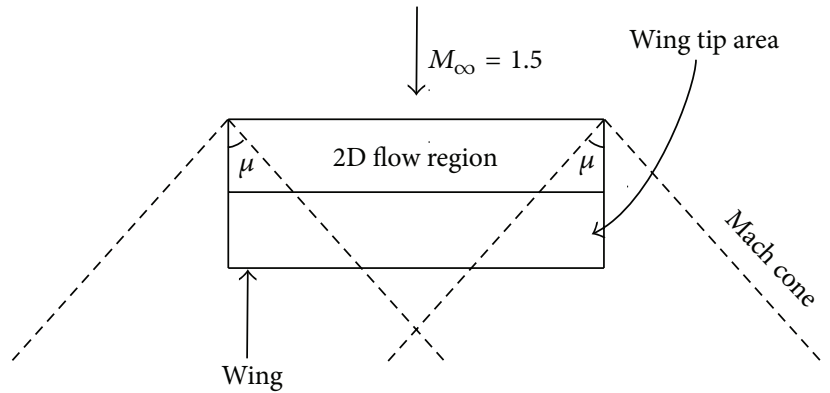

(b) Model B

FIGURE 14: Regions of influence in supersonic flow on finite biplane wings: (a) model A (AR $=0.75)$ and (b) model $B(A R=2.5)$. The illustrations show the upper surface of the lower wing element (plan view). The broken lines indicate the Mach cone generated from each tip at $M_{\infty}=1.5\left(\mu=41.8^{\circ}\right)$.

sweep and pitch pause runs. Two types of model were tested: $\mathrm{AR}=0.75$ (model $\mathrm{A})$ and $\mathrm{AR}=2.5$ (model $\mathrm{B})$. The results showed that the start/unstart characteristics of models A and $\mathrm{B}$ differed from those of the Busemann biplane (two dimensional) owing to three-dimensional effects. The two models were in the start state at lower Mach numbers than those of the Busemann biplane. The characteristics of models $\mathrm{A}$ and $\mathrm{B}$ also differed because these models had different aspect ratios. Model A appeared to be in the start state at lower Mach numbers $\left(1.3<M_{\infty}<1.5\right)$ than model B $\left(1.6<M_{\infty}<1.8\right)$ owing to the lower aspect ratio. The pitch pause run at $M_{\infty}=1.7$ showed that model B was located in the double solution domain for start/unstart characteristics and model B was in either the start state or unstart state at $M_{\infty}=1.7$. Once the state was determined, either state was stable.

\section{Nomenclature}

$A_{i}:$ Inlet area, $\mathrm{m}^{2}$

$A_{t}$ : Throat area, $\mathrm{m}^{2}$

AR: Aspect ratio $\left(=\mathrm{w}^{2} / \mathrm{S}=\mathrm{w} / \mathrm{c}\right)$

c: Chord length, $\mathrm{m}$

$f$ : Focal length, $\mathrm{m}$

$G$ : Distance between wing elements, $m$

$G^{*}$ : Distance between wing elements at the shoulder, $\mathrm{m}$
M: $\quad$ Mach number

$P$ : $\quad$ Pressure, $\mathrm{Pa}$

Re: $\quad$ Reynolds number

S: $\quad$ Wing area, $\mathrm{m}^{2}$; total model planform area, $\mathrm{m}^{2}$

$t$ : Wing thickness, $\mathrm{m}$

$w$ : Wing span, $m$

$x, y, z$ : Cartesian coordinates

$Z: \quad$ Section modulus, $\mathrm{m}^{3}$

$\alpha: \quad$ Angle of attack, deg

$\beta$ : $\quad$ Angle of yaw, deg

$\gamma: \quad$ Ratio of specific heats

$\mu$ : $\quad$ Mach angle, deg

$\sigma_{\max }: \quad$ Maximum stress, $\mathrm{Pa}$

$\sigma_{Y}: \quad$ Yielding stress, $\mathrm{Pa}$

$\phi$ : $\quad$ Diameter of window and mirror, $m$; angle of roll, deg.

\section{Subscripts}

0: Ambient; total

$\infty$ : Freestream.

\section{Conflict of Interests}

The authors declare that there is no conflict of interests regarding the publication of this paper. 


\section{Acknowledgments}

This work was supported financially by Grants-in-Aid for Scientific Research (no. 15206091 and no. 19206086) from the Ministry of Education, Culture, Sports, Science and Technology of Japan and the Tohoku University 21st Century Center of Excellence Program. The authors wish to thank Dr. K. Kusunose of JAXA and Professor K. Matsushima of Toyama University for their invaluable comments regarding this work. The authors would like to thank Dr. T. Irikado and Mr. K. Sato of ISAS/JAXA for their considerable support in performing wind tunnel tests. The authors would like to express their gratitude to Dr. M. Kurita of the Wind Tunnel Technology Center, JAXA, for his helpful suggestions regarding wind tunnel model design. The authors wish to acknowledge their colleagues, Dr. K. Shimoyama, Dr. A. Toyoda, and Mr. S. Ozaki, for their helpful technical assistance concerning wind tunnel tests.

\section{References}

[1] A. R. George and R. Seebass, "Sonic boom minimization including both front and rear shocks," AIAA Journal, vol. 9, no. 10, pp. 2091-2093, 1971.

[2] C. M. Darden, "Sonic boom theory: its status in prediction and minimization," Journal of Aircraft, vol. 14, no. 6, pp. 569-576, 1977.

[3] K. J. Plotkin, "State of the art of sonic boom modeling," Journal of the Acoustical Society of America, vol. 111, no. 1, part 2, pp. 530-536, 2002.

[4] J. J. Alonso and M. R. Colonno, "Multidisciplinary optimization with applications to sonic-boom minimization," Annual Review of Fluid Mechanics, vol. 44, pp. 505-526, 2011.

[5] K. Kusunose, "A new concept in the development of boomless supersonic transport," in Proceedings of the 1st International Conference on Flow Dynamics, pp. 46-47, Sendai, Japan, November 2004.

[6] K. Kusunose, K. Matsushima, Y. Goto et al., "A fundamental study for the development of boomless supersonic transport aircraft," AIAA Paper 2006-0654, 2006.

[7] K. Kusunose, K. Matsushima, S. Obayashi et al., Aerodynamic Design of Supersonic Biplane: Cutting Edge and Related Topics, vol. 5 of The 21st Century COE Program International COE of Flow Dynamics Lecture Series, Tohoku University Press, Sendai, Japan.

[8] K. Kusunose, K. Matsushima, and D. Maruyama, "Supersonic biplane-a review," Progress in Aerospace Sciences, vol. 47, no. 1, pp. 53-87, 2011.

[9] A. Busemann, "Aerodynamic lift at supersonic speed," Luftfahrtforschung, vol. 12, no. 6, pp. 210-220, 1935.

[10] H. W. Liepmann and A. Roshko, Elements of Gas Dynamics, John Wiley \& Sons, New York, NY, USA, 1957.

[11] H. Yamashita, S. Obayashi, and K. Kusunose, "Reduction of drag penalty by means of plain flaps in the boomless busemann biplane," International Journal of Emerging Multidisciplinary Fluid Sciences, vol. 1, no. 2, pp. 141-164, 2009.

[12] D. Maruyama, K. Kusunose, and K. Matsushima, "Aerodynamic characteristics of a two-dimensional supersonic biplane, covering its take-off to cruise conditions," Shock Waves, vol. 18, no. 6, pp. 437-450, 2009.
[13] K. Matsushima, K. Kusunose, D. Maruyama, and T. Matsuzawa, "Numerical design and assessment of a biplane as future supersonic transport-revisiting busemann's biplane," in Proceedings of the 25th Congress of International Council of the Aeronautical Sciences (ICAS '06), CD-ROM Proceedings, pp. 1-10, Optimage Ltd., Hamburg, Germany, September 2006.

[14] D. M. van Wie, F. T. Kwok, and R. F. Walsh, "Starting characteristics of supersonic inlet," AIAA Paper 1996-2914, July 1996.

[15] D. M. van Wie, M. E. White, and P. J. Waltrup, "Application of computational design techniques in the development of scramjet engines," AIAA Paper 87-1420, June 1987.

[16] D. M. van Wie and S. Molder, "Applications of busemann inlet designs for flight at hypersonic speeds," AIAA Paper 92-1210, February 1992.

[17] S. Molder and E. J. Szpiro, "Busemann inlet for hypersonic speeds," Journal of Spacecraft and Rockets, vol. 3, no. 8, pp. 13031304,1966

[18] M. H. Aksel and O. C. Eralp, Gas Dynamics, Chapter 5, Prentice Hall, Englewood Cliffs, Calif, USA, 1994.

[19] N. Kuratani, T. Ogawa, H. Yamashita, M. Yonezawa, and S. Obayashi, "Experimental and computational fluid dynamics around supersonic biplane for sonic-boom reduction," AIAA Paper 2007-3674, May 2007.

[20] N. Kuratani, M. Yonezawa, H. Yamashita, S. Ozaki, T. Ogawa, and S. Obayashi, "Wing configuration effects on flow field and aerodynamic performance of supersonic biplane for sonicboom reduction," in Proceedings of the 26th Congress of International Council of the Aeronautical Sciences (ICAS '08), CD-ROM Proceedings, pp. 1-10, Optimage Ltd., Anchorage, Alaska, USA, September 2008.

[21] “9-by 7-foot Supersonic Wind Tunnel," May 2013, http://www. windtunnels.arc.nasa.gov/9x7ft1.html.

[22] A. Pope and K. L. Goin, High-Speed Wind Tunnel Testing, Chapters 2, 8 and 10, Wiley, New York, NY, USA, 1965.

[23] H. Yamashita, T. Fujisono, A. Toyoda et al., "Aerodynamic characteristics and effects of winglets of the boomless tapered supersonic biplane during the starting process," Transactions of the Japan Society for Aeronautical and Space Sciences, Aerospace Technology Japan, vol. 11, no. 1, pp. 17-26, 2013.

[24] T. Irikado, K. Sato, and K. Fujii, "Transient loads and flow structures in the ISAS supersonic wind tunnel," in Proceedings of 38th Fluid Dynamics Conference, pp. 259-262, Muroran, Japan, September 2006.

[25] T. Irikado, K. Sato, and K. Fujii, "Transient flow in the ISAS supersonic wind tunnel," in Proceedings of 40th Fluid Dynamics Conference/Aerospace Numerical Simulation Symposium, pp. 231-234, Sendai, Japan, June 2008. 

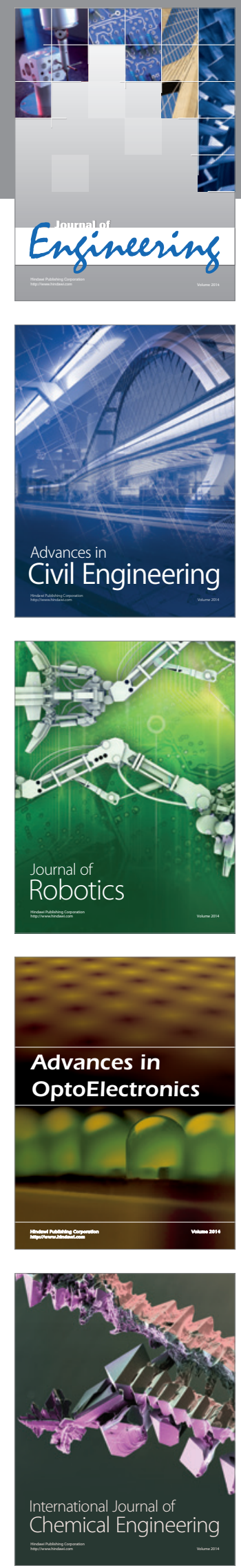

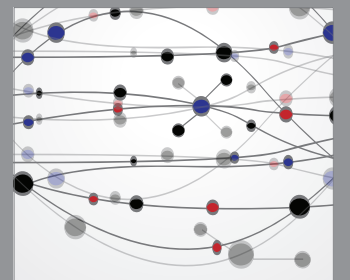

The Scientific World Journal
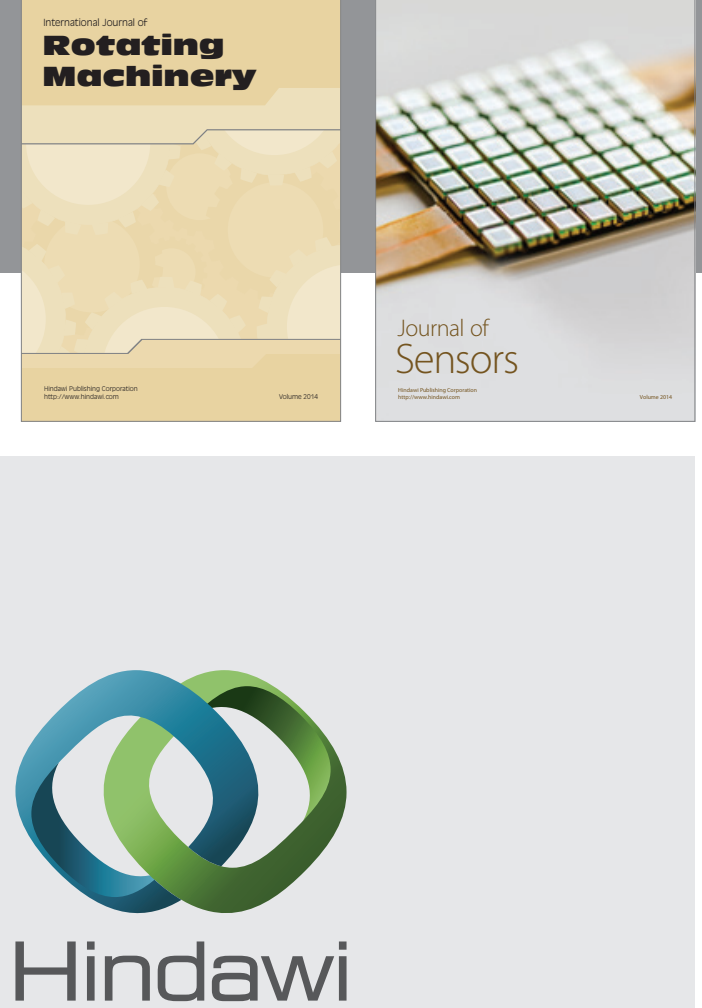

Submit your manuscripts at http://www.hindawi.com
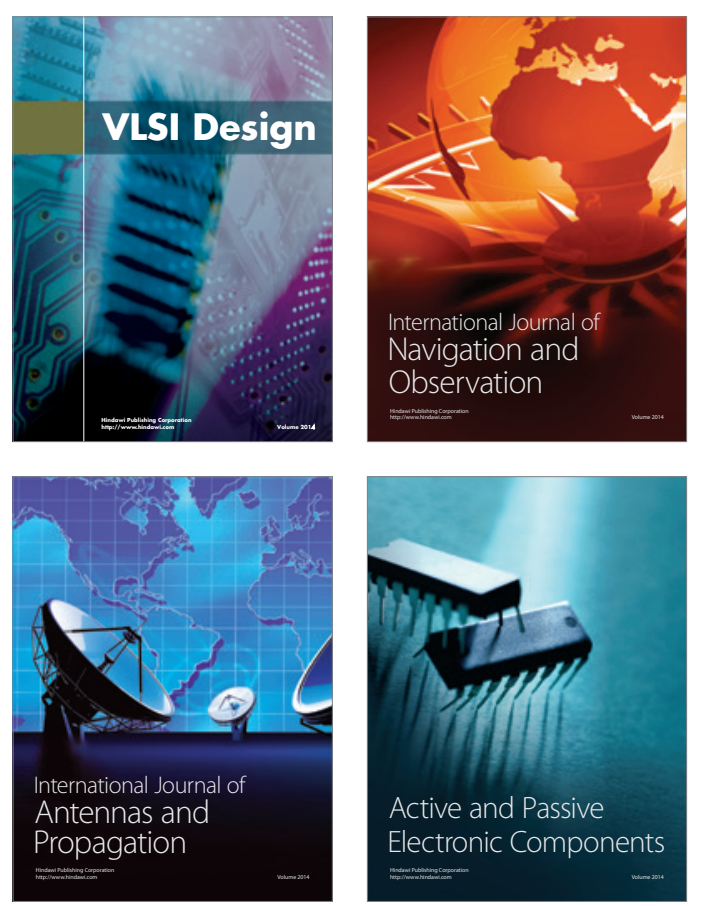
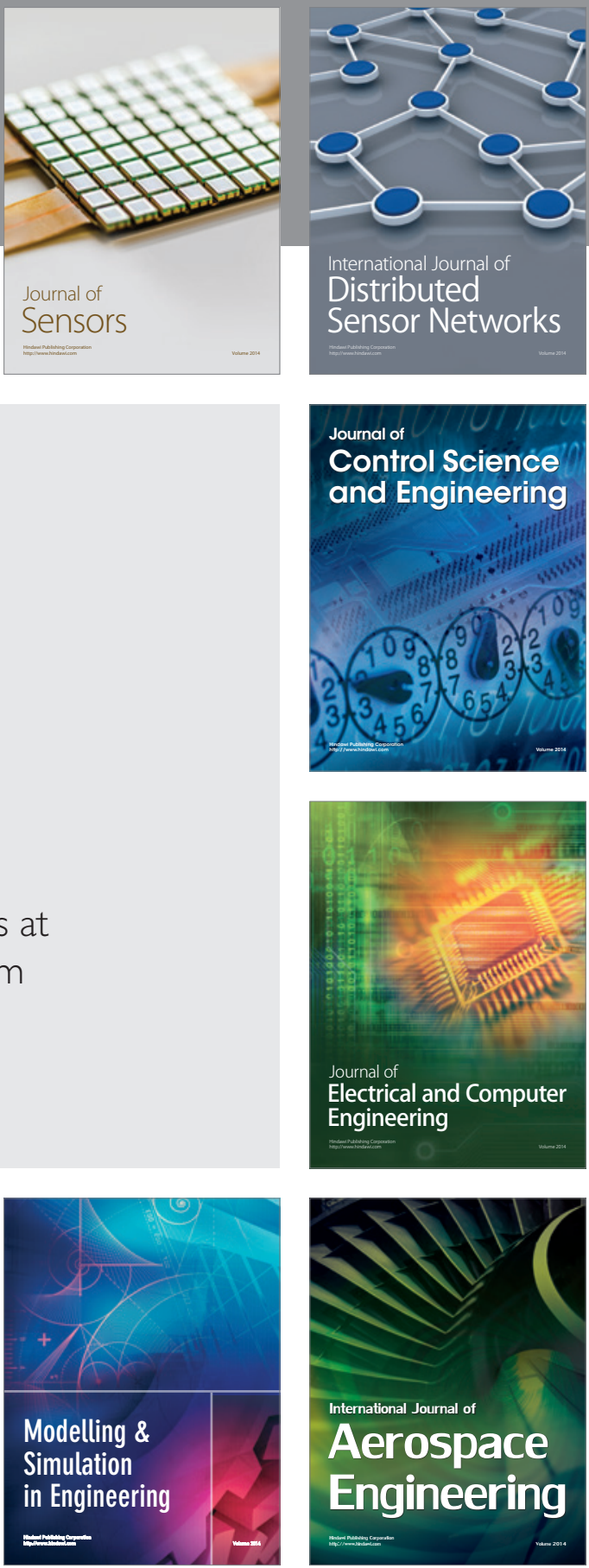

Journal of

Control Science

and Engineering
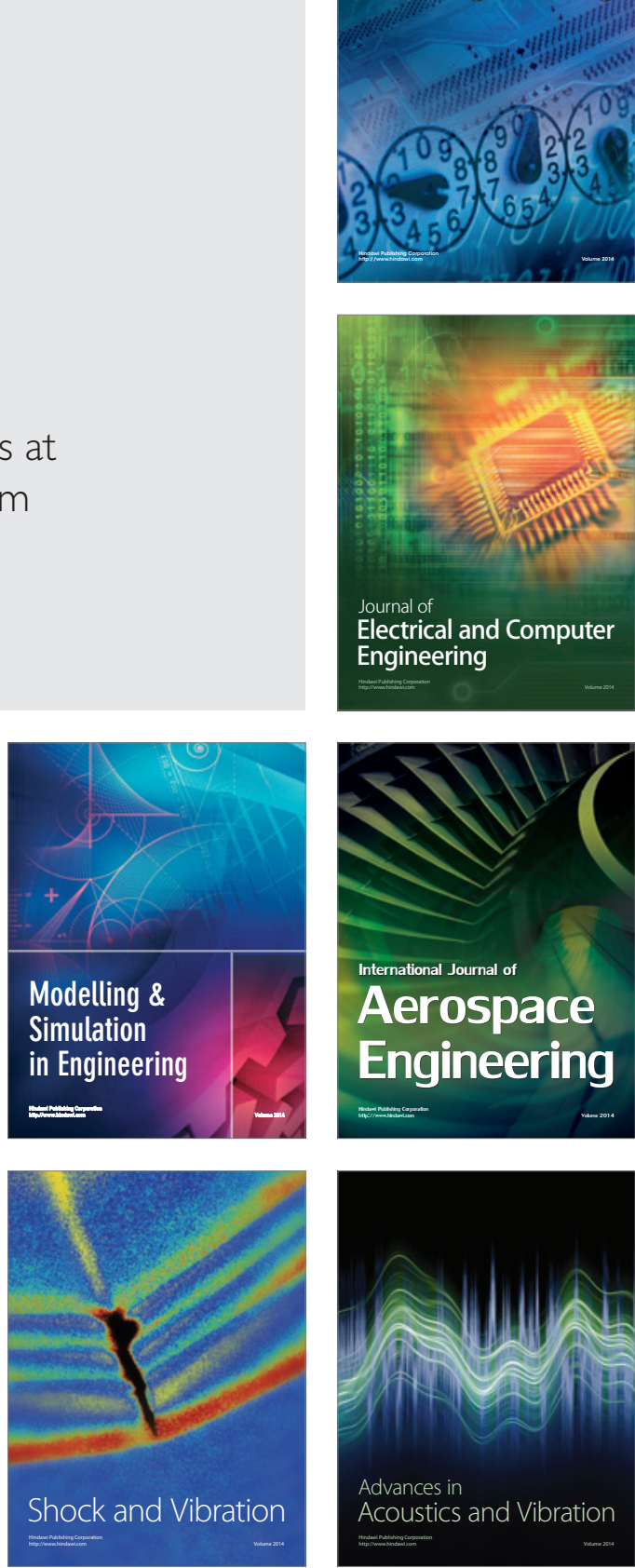